Article

\title{
Nurturing Environmental Education at the Tertiary Education Level in China: Can Mobile Augmented Reality and Gamification Help?
}

\author{
Bing Mei ${ }^{1}$ and Shuxia Yang ${ }^{2, *(\mathbb{D})}$ \\ 1 School of Foreign languages, Henan University, 85 Minglun Street, Kaifeng 475001, Henan, China \\ 2 Institute of Foreign Linguistics and Applied Linguistics, Henan University, 85 Minglun Street, \\ Kaifeng 475001, Henan, China \\ * Correspondence: hdysx@henu.edu.cn
}

Received: 7 July 2019; Accepted: 6 August 2019; Published: 8 August 2019

check for updates

\begin{abstract}
In the educational context, there currently emerges a growing research interest in using mobile augmented reality (AR) and the gamification concept to promote environmental education (EE). However, to date, scant attention has been paid to practically linking this approach to formal curricula at the tertiary level in China. Given the situation, we designed a geolocation-based mobile AR scavenger hunt to explore students' perception of embedding technology-enhanced and gamified $\mathrm{EE}$ in their language learning process. Ninety-eight first-year students, majoring in English at a Chinese university, were invited to participate in this study. In this game, students need to find the answers to 24 environment-themed questions phrased in English. Guided by prior technology acceptance research, we employed a mixed methods approach to capture participants' experience and perception of the process. The results show that this approach was positively perceived among the participants, for it could not only enrich their language learning experience but also promote their awareness of the environment. The findings offer insights into how EE can be purposefully integrated with tertiary education by leveraging current technological and pedagogical innovations.
\end{abstract}

Keywords: environmental education; educational technology; gamification; technology-enhanced learning; tertiary education

\section{Introduction}

Educational researchers have long noticed the value of integrating environmental education (EE) into formal curricula to promote environmental protection and sustainable development among citizens [1-3]. Recent research suggests that over the years, rapid progress has been made in China with students being provided opportunities at schools for EE [4]. However, despite the promising progress, research has also indicated that current efforts mainly target students at elementary and secondary levels [5], and the exploration of integrating EE into the formal curricula at the tertiary level still remains relatively limited [6]. Meanwhile, given the release of The United Nations 2030 Agenda for Sustainable Development, how to educate university students in China to be environmentally responsible has become increasingly prominent.

Recently, with the exponential growth of information and communication technology (ICT), mobile computing devices have become commonplace among university students [7,8]. Along with this trend, there also emerges a research interest in gamifying EE in recent years [9-14]. However, at present, it is not rare for university teachers to characterize mobile devices as detrimental to the quality of university education. For some of them, mobile devices' side effects in classrooms outweigh their potentials; and mobile device-based gamification is an even worse adversary $[15,16]$. 
Against this backdrop, the current study seeks to explore how EE, mobile augmented reality (AR) and gamification can function together as a low-cost, dynamic, and accessible system at the tertiary level in China. Moreover, guided by prior technology acceptance research, we hope that the findings of the present study could help reveal university students' perception and attitude towards this approach and offer insights into how such a combination can be tailored for tertiary education. Last but not least, it is also our hope that the findings can inform similar explorations in the future and provide educational policy makers with empirical evidence in the decision-making process.

\section{Literature Review}

\subsection{Mobile AR and EE}

Van Krevelen and Poelman [17] (p. 1) defined AR as a medium that "combines real and virtual objects in a real environment, registers (aligns) real and virtual objects with each other, and runs interactively in three dimensions and in real time". Thanks to the rapid evolution of ICT, AR has already stepped out of research labs and become increasingly commonplace in our daily life. In the meantime, alongside the widespread popularity of mobile devices (e.g., smartphones and tablet computers), recent years have witnessed a steady growth of research interest in exploring possible opportunities to link mobile AR to EE. For example, in their effort to improve middle school students' understanding of ecosystem science, Kamarainen et al. [10] designed a field trip to a local pond for a group of middle school students $(N=71)$ on the basis of mobile AR and handheld environmental probes. Their findings reveal that the use of mobile AR can keep students highly engaged with the content knowledge and help them link what they learn in classrooms to the outdoor reality. Lu and Liu [18] conducted a quasi-experimental study on using mobile AR for in-classroom marine education in an elementary school in Taiwan. Fifty-one students, aged 7-8 years, participated in two mobile AR-based learning activities. Their findings suggest that both teachers and students have positive attitudes towards these activities, which motivated collaborative learning among students and improved their learning outcomes. Recently, due to the significant improvement of smartphone's processing capacity, a wide range of mobile AR-based apps have been developed to raise public awareness of the environment. Taking advantage of the cameras, sensors, and screens embedded within smartphones, these apps provide learners with instant feedback and immersive AR experiences in their learning of the natural environment. Some well-known examples include Sky Guide AR [19] for identifying constellations, PlantSnap: Plant Identification [20] for recognizing plants nearby, and Monash Rocks [21] for naming rocks in the Monash Earth Sciences Garden.

\subsection{Gamification and $E E$}

According to Khan, Ahmad, and Malik [22] (pp. 2769-2770), gamification refers to the practice of "adding game design elements e.g., feedback, challenge, points to a non-gaming environment to promote active learning in conventional classrooms, increase student engagement and motivation, and help in achieving certain learning outcomes". Recent findings indicate that gamification has been another rising research direction in EE. For instance, embracing the concept of gamification, Yang and Chen [23] designed discovery maps for visitors of a botanical garden located in southwest China. They found that scaffolding the garden visit with gaming activities could keep visitors deeply engaged and significantly enhance their knowledge of the biodiverse ecosystem. In another study, Eisenack [24] reported the effect of playing a board game, KEEP COOL, on the development of students' awareness of climate change. The findings suggest that through in-game discussion and collaboration, students gained a holistic understanding of different factors associated with climate change. Moreover, in their review of serious games for water management education, Savic, Morley, and Khoury [25] pointed out that there is a need to explore possible links among serious games, handheld digital devices, and EE. 


\subsection{Technology Acceptance}

With the advent of ICT in the 1970s, technology acceptance research emerged in business context in order to cope with users' reluctance to use technology in organizational settings [26]. According to Teo [27] (p. 1), technology acceptance refers to "a user's willingness to employ technology for the tasks it is designed to support". The basic tenet for technology acceptance research is that users' beliefs influence their intention to use technology, which, in turn, influences their adoption of technology in reality $[28,29]$. With the increase of ICT initiatives in the educational context, users' reluctance and concerns about ICT for teaching and learning purposes arose [30]. Guided by technology acceptance research, educational researchers have identified a wide range of factors to build positive relations between users and ICT [31]. Some of the most well-known ones include perceived usefulness, perceived ease of use, attitude towards technology, and behavioral intention to use technology.

In sum, the literature review suggests that research that endeavors to combine EE, mobile AR, and gamification has started to gain momentum. However, it also reveals that the current efforts mainly focus on informal learning and there currently exists a paucity of research on practical solutions to link this approach to formal learning, especially at the tertiary level. Moreover, though educational researchers around the world are increasingly drawing inspirations from AR and gamification, less is known about university students' views towards the formal learning process incorporating mobile AR-assisted and gamified EE. Therefore, in the current study, we tested a practical way to link mobile AR-assisted and gamified EE to an English lesson among a group of Chinese university students, and to ascertain their acceptance of this approach.

This study aimed to address the following two questions:

1. Is it a plausible approach to link EE to tertiary education by leveraging mobile AR and gamification?

2. How do university students perceive this approach?

\section{Method}

\subsection{Research Design}

Given the scope of this study, we adopted an explanatory sequential mixed methods design [32], which is shown in Figure 1 in detail.

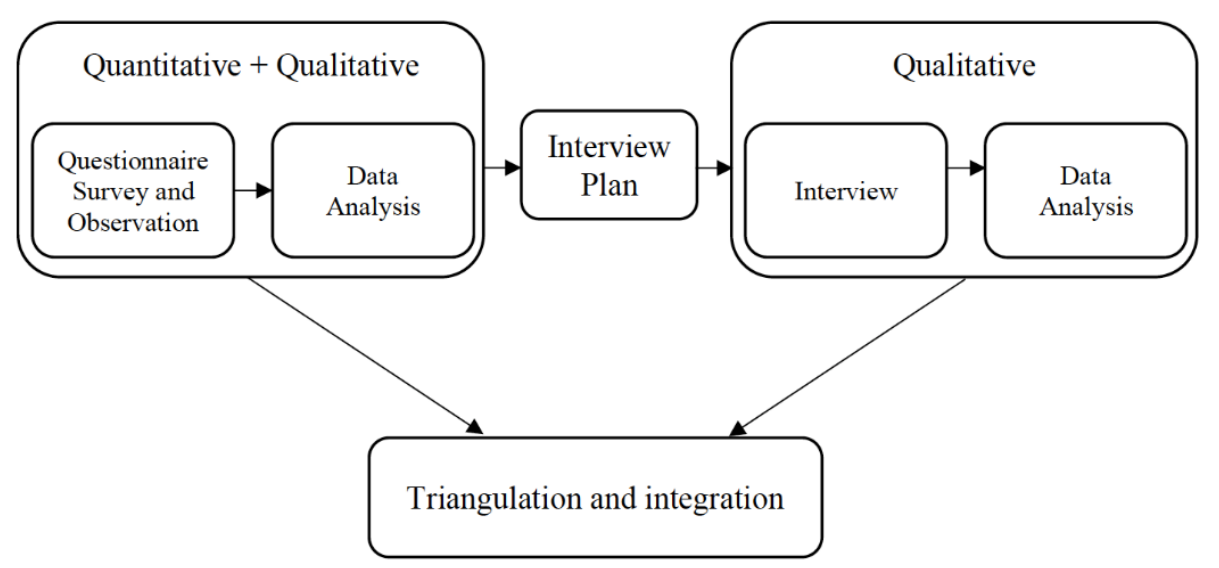

Figure 1. The schematic presentation of the explanatory sequential mixed methods design for this study.

Guided by prior technology acceptance research, we solicited a group of first-year university students' views about embedding a mobile AR-based and environment-themed scavenger hunt into an English writing course. The choice of choosing English language education is mainly due to the following two considerations: (1) the application for running this game currently only has an English version and (2) English language education is an important part of university education in China [33]. 


\subsection{Study Site and Participants}

This study was conducted at a comprehensive university located in central China. Thanks to the rapid economic development and growing public awareness of the environmental education in recent years, institutional efforts such as setting up signages, providing recycling bins, and organizing environment-themed activities have been made to increase students' environment awareness. However, currently, explorations on linking EE to formal curricula in practice remain scant at this institution.

A convenience sampling strategy was adopted to recruit participants in this study. The first-year students enrolled in an English-as-a-Foreign-Language program at this institution were invited to participate in this study. The final sample consisted of 87 females and 11 males, whose age ranged from 17 to $20(M=18.31, S D=0.86)$.

Furthermore, following Palinkas et al.'s [34] recommendation, we employed a purposeful sampling strategy to select follow-up interviewees in order to ensure efficiency and validity. On the basis of their responses, invitations were sent to a subset of 10 participants for a follow-up interview, and five of them, whose attitudes towards the approach ranged from strongly disagree to strongly agree in the questionnaire survey, accepted the invitation and participated in the follow-up interview.

\subsection{Ethical Considerations}

All procedures performed in this study were in accordance with the ethical standards of the local institution. Before this study, all participants were informed of the purpose of the study and guaranteed that their participation in or withdrawal from this study would incur neither reward nor punishment.

\subsection{Materials}

Drawing on prior research [35-37], we employed ARIS [38] in designing the game. ARIS, as a free and open-source platform, provides an innovative way to design mobile AR-based learning and teaching. The platform allows educators to design geolocation-based games, tours, and interactive stories to create learner-centered activities and collaborative learning experience. For example, in a typical ARIS scenario, students would usually take charge to actively collaborate to solve puzzles, while teachers mainly act like facilitators, addressing unexpected issues.

Given that one aim of this study is to increase students' engagement with the campus environment, the ARIS-based game in our study consists of both technical and physical elements. With regard to the technical side, it includes an ARIS game that runs on students' handheld digital devices. Students need to follow the in-app clues to reveal five target destinations in order. Figure 2 presents the on-screen interface and components of the game.

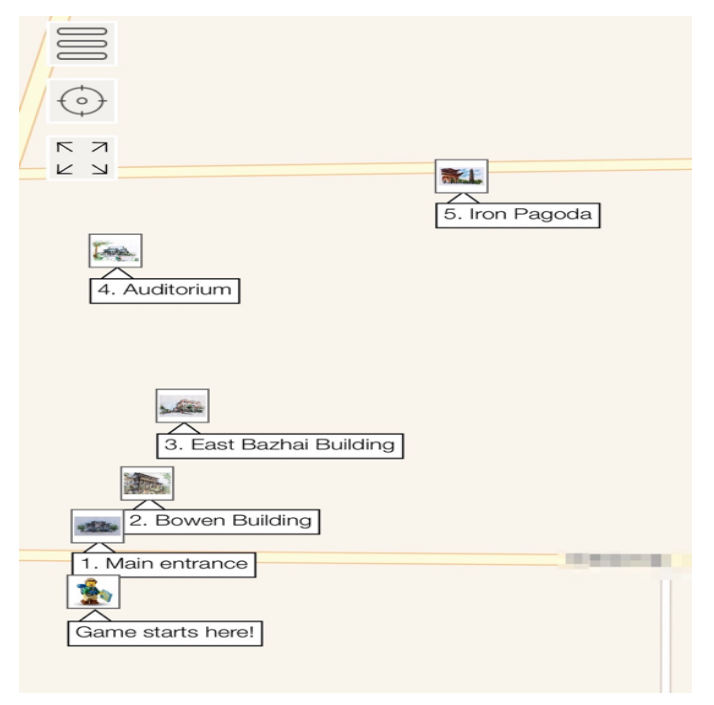

Figure 2. The on-screen game interface with all five target destinations being unlocked. 
Meanwhile, a paper worksheet with 24 English questions, which are purposefully phased around the biodiversity and sustainable lifestyle, is also provided (e.g., find various plants in the campus garden, describe their features in English, and discuss how the buildings on campus reflect the Chinese ancient doctrine of harmony between heaven and the people). With this design, the game has the following two learning objectives: (1) to direct students' attention to the environmental aspects in their campus life instead of the technology itself and (2) to master English expressions related to the campus environment.

\subsection{Procedure}

Due to the limited number of equipment, participants were divided into teams and each team was provided with an iPhone with internet access. When the game started, students followed the on-screen geolocational guidance to reach pre-determined target destinations in order to unlock the next target location. However, before they leave for the next destination, students also needed to read the instruction, check the surrounding environment for correct answers, and document them on the worksheets. All teams successfully found correct answers to the 24 questions, but it was the first team handing in their worksheets that was declared the winner of this game. Afterwards, the teacher summarized the activity in the classroom. See Appendix A for the lesson plan.

\subsection{Data Collection}

In this study, data were collected through field notes, an online questionnaire, and semi-structured interviews.

First, one researcher, who monitored the game, took detailed field notes of each group by following the guidelines suggested by Emerson, Fretz, and Shaw [39]. The notes focused on documenting participants' in-game performance, especially their interaction and engagement with the game, as is shown in Figure 3.

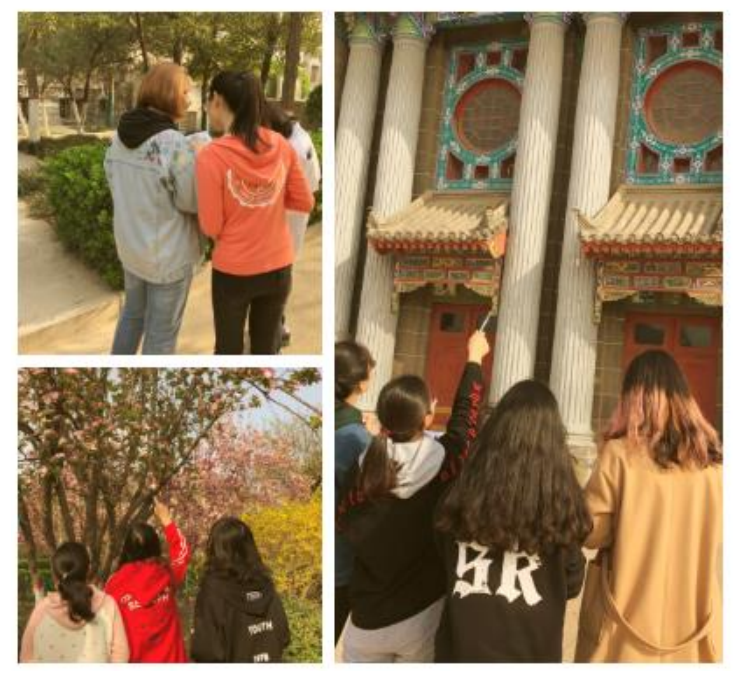

Figure 3. Field note examples.

Next, after the game, participants were invited to complete an online self-reported questionnaire. The purpose of the questionnaire was to gauge students' perception of this approach for EE. Informed by prior technology acceptance research, we designed a questionnaire focusing on four constructs: perceived usefulness (three items; adapted from Davis [26]), perceived ease of use (three items; adapted from Davis [26]), attitude towards the game (three items; adapted from Chau and $\mathrm{Hu}$ [40]), and behavioral intention (three items; adapted from Teo [41]).

In the adaptation process of the items, changes were made in wording to fit the specific theme of the research. A 5-point positively packed scale recommended by Brown [42] was employed to 
measure students' level of agreement (i.e., $1=$ strongly disagree, $2=$ disagree, $3=$ agree, $4=$ mostly agree, and $5=$ strongly agree). To help participants understand the questionnaire easily and precisely, these questions were translated into Chinese. After that, two experts, who have psychometric research experience, were consulted to check its content validity.

Two days after the game, face-to-face interviews were arranged for the selected participants. Each interview lasted approximately $30 \mathrm{~min}$, during which, questions such as how they perceived the game, what the possible reasons were for their perception, and whether they would like to participate in similar activities in the future were asked. The semi-structured interviews were conducted in Chinese, audio recorded, and transcribed verbatim.

\subsection{Data Analysis}

Data were computerized and analyzed in two phases. In the first phase, quantitative data were imported into Statistical Packages for Social Sciences 23.0 for statistical analysis. Next, the internal consistency of the questionnaire items was checked, and all Cronbach's alpha values were above the threshold value of 0.70 recommended by Nunnally [43], suggesting the presence of internal consistency. Then, the mean scores and standard deviations for the variables were calculated to provide descriptive statistics, including the proportion of subjects, percentages and average in order to summarize information and identify potential interviewees.

Moreover, in line with Creswell and Miller's [44] recommendation, both field notes and interview transcripts collected at different times were imported into NVivo to offset subjectivity and research bias. Following that, the other researcher, who was not involved in the fieldwork and face-to-face interview, analyzed the data with a directed content analysis approach [45]. During the process, an initial code template around the pre-determined four themes (i.e., perceived ease of use, perceived usefulness, attitude towards participation, and intention to participate) was used to code the data. After all the transcripts were coded, each theme was re-examined to check the common patterns.

\section{Results}

\subsection{Phase 1 Results}

A total of 98 participants of this study responded to the 12 items on the questionnaire, presenting their general perceptions of this approach for EE. Table 1 shows the measure of central tendency and dispersion for each item.

Table 1. Descriptive statistics for the questionnaire items $(N=98)$.

\begin{tabular}{ccccc}
\hline Item & M & SD & Skewness & Kurtosis \\
\hline PU1 & 4.35 & 0.86 & -1.23 & 1.23 \\
PU2 & 4.08 & 0.97 & -0.65 & -0.43 \\
PU3 & 4.09 & 1.02 & -0.88 & -0.13 \\
PEU1 & 3.58 & 1.01 & -0.41 & 0.02 \\
PEU2 & 3.88 & 0.92 & -0.39 & -0.33 \\
PEU3 & 3.89 & 1.00 & -0.76 & 0.38 \\
ATP1 & 4.58 & 0.77 & -1.71 & 1.88 \\
ATP2 & 4.57 & 0.77 & -1.54 & 0.97 \\
ATP3 & 4.47 & 0.81 & -1.18 & -0.05 \\
ITP1 & 4.56 & 0.76 & -1.50 & 0.97 \\
ITP2 & 4.37 & 0.87 & -1.07 & 0.019 \\
ITP3 & 4.35 & 0.86 & -1.23 & 1.23 \\
\hline
\end{tabular}

Note. $\mathrm{PU}=$ perceived usefulness; PEU = perceived ease of use; ATP = attitudes towards participation; ITP = intention to participate. 
All means were above 3.00, ranging from 3.58 to 4.58 . The standard deviations ranged from 0.76 to 1.02 , indicating a fair spread around the mean. The examination of the univariate normality of these items showed that the data were generally normally distributed.

The self-report responses to perceived usefulness from the participants suggest that they generally agreed that it is a useful practice to integrate EE into university curricula with the assistance of mobile $\mathrm{AR}$ and gamification (Ms $>4.00$ ).

With regard to their agreement with perceived ease of use, the results suggest that the participants had no difficulty in interacting with the technology involved in this study. However, it also should be noted that the item with the lowest agreement was found in this category (Ms $<4.00$ ), accentuating the need for technological consideration when planning similar projects in future.

As for their attitudes, it seems that participants generally held favorable attitudes towards this approach for EE (Ms > 4.50), suggesting that they understand and appreciate the embedded educational value.

When asked about their intention to participate again, respondents showed their strong willingness to participate in similar activities in the future and to share their experiences with their peers (Ms $>4.00$ ).

\subsection{Phase 2 Results}

In order to gain an in-depth understanding of students' perception of the approach, the coded interview transcript segments-both negative and positive-were grouped, categorized, and connected to labelled field notes in NVivo around the four pre-determined themes: perceived ease of use, perceived usefulness, attitude towards participation, and intention to participate. The five interviewees were coded as ST1 to ST5 for the purpose of identity protection.

First, most students considered this approach useful because when playing this game, they could easily relate the target language to the natural environment and create more meaningful and engaging learning experiences with their peers.

- $\quad$ This game is very useful in learning because when playing this game, I not only learned new English vocabularies with electronic dictionaries, but also got improved in environmental knowledge by searching the Internet for the answers to the questions on the worksheet. (ST1)

- I think this game is useful because by integrating environmental education into language learning, this game provided us with the opportunity to reflect on environmental issues in English. Language education should not be limited to teaching language skills; it should also focus on developing students' responsibility awareness. I think the game we played achieved this goal. (ST2)

- This game afforded me the opportunity to carry out self-learning. Instead of passively getting information from teachers' lecture, I could explore the environment by myself and find the missing information by searching the Internet and communicating with my classmates. (ST4)

- I was impressed with the learning mode created by this game. I am not good at using digital products at all, but this game offered me the opportunities to learn from my classmates how to use technology in learning. (ST5)

Next, four interviewees reported that the digital technologies involved in this approach for EE were easy to operate, and three of them stated that they could easily achieve what they intended to do with the help of digital technologies. Some illustrative comments are listed below.

- It might require a lot of energy and time to learn how to use technology in learning in the past, but things are different nowadays. The apps installed on my phone are easy to use, and I easily found the missing information on the worksheet with the help of my phone. (ST2)

- $\quad$ Take the app I am using for example. Its plant-recognizing function benefited me a lot. I easily found the answers to the questions on the worksheet without typing a word. (ST3) 
Additionally, three interviewees expressed positive attitudes towards the approach. They considered it a pleasant learn-though-play experience and agreed that this approach would not only benefit their language learning, but also contribute to their personal development.

- This game was fun. I enjoyed playing it. I think it is a good idea to integrate environmental education into language education, because it can help me develop critical thinking skills, make more friends, and expand my vocabulary. (ST1)

- I like this game and hope we can have more activities like this. I think the integration of technology, environmental education, and language education would benefit my whole university learning process and broaden my vision. (ST3)

Furthermore, four interviewees expressed their intention to take part in similar activities in future. Two of them mentioned that they have already shared this experience with friends through social media and they further expressed their willingness to take courses that link EE and language learning on the basis of mobile AR and gamification. Some of the remarks are listed below.

- I had such a great fun in this game and have already shared this learning experience with my friends through WeChat. (ST2)

- I hope we can have more opportunities to participate in similar activities in the future, for this is what tertiary education should be in my mind. (ST3)

However, besides the positive voices, the analysis of the field notes did reveal two major issues when students were playing the game. Firstly, some students experienced technology-related issues: (1) the ARIS app would quit unexpectedly sometimes, posing a threat to the users' experience; (2) the small screen size and the limited number of devices made it difficult for students to share the information on time; and (3) some students using their own devices, received phone calls or message notices during the game, which tended to disrupt the learning process. Secondly, although this approach seemed intuitive to technology-savvy students, some students tended to stay passive rather than actively collaborative in the game.

\section{Discussion and Implications}

This study aimed to explore plausible ways to link EE to tertiary education in China. To this end, we examined a group of university students' perception of integrating mobile AR-assisted and gamified EE into their language learning process. Overall, the quantitative and qualitative findings confirmed that participants found such an integration useful and effective for both EE and foreign language learning. Participants generally agreed that such an integration not only benefited their language learning but also improved their environmental knowledge and awareness of environmental issues. This finding is consistent with previous research which found that innovative and engaging activities based on ubiquitous mobile technology and gamification can help students gain more cognitive, affective and participatory environmental knowledge, and hence provoke students' interests in environmental subjects and promote their environmental awareness [46,47].

With regard to perceived ease of use, the quantitative results revealed that participants generally had no difficulty in interacting with the technology involved in this study, but the field notes and the quantitative analysis did indicate the need for technological consideration and pedagogical design before implementing similar activities in future to avoid possible digital downsides such as unnecessary annoyances and interruption [48]. Meanwhile, the qualitative analysis revealed that participants enjoyed this self-learning experience. Even those students struggling with technology replied positively, stating that this game provided them with opportunities to learn from their peers. This finding is in line with the benefits identified in previous research on linking mobile technology and outdoor activities in the educational context $[49,50]$, suggesting that the new learning opportunity could create a student-centered teaching and learning environment in which students are encouraged to collaborate and learn from each other. 
Next, both quantitative and qualitative results demonstrated that, overall, participants held a favorable attitude towards linking EE and foreign language learning with the help of mobile AR and gamification. Participants valued such an integration because they thought it could develop their reflective thinking skills and benefit their language learning process. This finding lends support to previous research that reported the development of students' cognitive knowledge and reflective thinking skills in similar practice [51].

Echoing Dirkx's [52] opinion about the power of feelings in motivating learning among adults, the results of the present study revealed that, viewing it as a pleasant experience, participants were generally willing to take part again in similar activities and to take courses that incorporate mobile $\mathrm{AR}$ and gamification to create meaningful learning experience. Though the learning experience was positively viewed by most students, some students' unwillingness to collaborate with their peers reiterates the importance of considering students' personalities in designing effective e-learning activities [53].

In summary, the findings in the present study show the promise of linking EE and formal curricula at the tertiary level by leveraging mobile AR and gamification. We believe that learning opportunities afforded by this approach can contribute to both the enhancement of students' learning experience and the development of students' environmental awareness and reflective thinking skills. Thus, this approach has pedagogical importance and should be noticed by policy makers and learning designers. However, in the design of similar projects in the future, attention should also be paid to the digital downsides (e.g., distraction and shortage of devices) by providing meaningful instructional design. Useful components such as achievable learning objectives, tangible worksheet, and prompt peer feedback can be employed to keep all students engaged in the learning process.

\section{Limitations and Recommendations for Future Research}

Although empirical support is present, this study does have several limitations. First, all participants in the present study were from one university. This may reduce the generalizability of the findings to the tertiary education sector. Next, though an explanatory sequential mixed methods research design was adopted, this study did not track the change in students' environmental knowledge before and after the game. Thus, paired sample tests can be carried out in future research to determine the effectiveness of similar activities in increasing university students' understanding of the environment. Furthermore, research can also be conducted to compare students' behavioral change before and after playing the game. Last but not the least, future research could also include university teachers as participants, for they may have different perceptions towards the approach.

\section{Conclusions}

With the growing recognition of the importance of EE to a modern society, there emerges a need for effective and engaging ways to promote EE in the educational context in China. Considering the increasing popularization of mobile digital devices among Chinese universities students, in this study, we explored the plausibility of linking EE to tertiary education by leveraging mobile AR and gamification. The results demonstrate that it can be a promising approach to operationalize EE at the tertiary education level in China. Though technical and instructional issues have been identified, feedback from students suggests that this approach can increase students' environmental awareness and subject content knowledge in an engaging way. As such, the results of this study could inform key stakeholders (e.g., policy makers, school leaders, and teacher educators) on how to take measures to better promote EE at the tertiary level in China.

Author Contributions: Conceptualization, B.M.; methodology, B.M.; quantitative data analysis, B.M.; qualitative data analysis, S.Y.; resources, S.Y.; data curation, S.Y.; writing-original draft preparation, B.M. and S.Y; writing-review and editing, B.M. and S.Y.; funding acquisition, S.Y. 
Funding: This study was funded by the Teacher Education Reform Project of Henan Provincial Educational Department (grant number: 2019-JSJYYB-011) and the Innovative Research Project of Henan University (grant number: 2019CXTD007).

Acknowledgments: The authors would like to thank all the students whose participation made this study possible.

Conflicts of Interest: The authors declare no conflict of interest.

\section{Appendix A}

\begin{tabular}{|l|}
\hline \multicolumn{1}{|c|}{$\begin{array}{c}\text { Lesson Plan } \\
\text { Our Campus }\end{array}$} \\
\hline Duration: 100 min \\
\hline Topic \\
Campus environment \\
Relevant English expressions (e.g., adjectives, nouns, and spatial prepositions) about describing natural \\
environment and indicating location \\
\hline Learning objectives \\
Students can master English expressions associated with the natural environment of the university campus \\
and the use of prepositions when indicating direction. \\
Students can apply their language skills to learn how the English app, ARIS, works and how to use it to \\
navigate. \\
Students can locate the pre-determined five places of interest on the university campus by following the \\
instruction of the ARIS app. \\
Students can participate in teamwork to develop collaborative skills. \\
\hline Lesson outline \\
1. Introduction (15 min) \\
The teacher brief students about the topics for this lesson and help students start with the ARIS app. \\
2. The scavenger hunt (60 min) \\
Students start working as groups to complete one work sheet. \\
3. Conclusion (25 min) \\
Students return to the classroom for discussion and feedback. \\
Learning outcomes \\
After completing this activity, students should be able to apply their English skills in practice (e.g., using \\
similar English app and introducing the campus in English). \\
After completing this activity, students should be more aware of the campus environment. \\
\hline
\end{tabular}

\section{References}

1. Aksan, Z.; Çelikler, D. The development of a recycling awareness scale for prospective science teachers. Educ. Stud. 2017, 43, 567-583. [CrossRef]

2. Stapp, W.B. The concept of environmental education. Am. Biol. Teach. 1970, 32, 14-15. [CrossRef]

3. Peter, M.; Diekötter, T.; Kremer, K. Participant outcomes of biodiversity citizen science projects: A systematic literature review. Sustainability 2019, 11, 2780. [CrossRef]

4. Efird, R. Learning places and 'little volunteers': An assessment of place- and community-based education in China. Environ. Educ. Res. 2015, 21, 1143-1154. [CrossRef]

5. UNESCO. Biodiversity Learning Kit; United Nations: Paris, France, 2017.

6. Fraser, N. The Environmental Toolkit for Teachers: First Steps to Sustainability; Bloomsbury: London, UK, 2014.

7. Galanek, J.D.; Gierdowski, D.C.; Brooks, D.C. ECAR Study of Undergraduate Students and Information Technology; Educasue: Louisville, CO, USA, 2018.

8. The 41st Statistical Report on China Internet Development. Available online: https://cnnic.com.cn/IDR/ ReportDownloads/201807/P020180711391069195909.pdf (accessed on 23 August 2018).

9. Greenhow, C.; Lewin, C. Social media and education: Reconceptualizing the boundaries of formal and informal learning. Learn. Media Technol. 2016, 41, 6-30. [CrossRef]

10. Kamarainen, A.M.; Metcalf, S.; Grotzer, T.; Browne, A.; Mazzuca, D.; Tutwiler, M.S.; Dede, C. EcoMOBILE: Integrating augmented reality and probeware with environmental education field trips. Comput. Educ. 2013, 68, 545-556. [CrossRef] 
11. Rahman, A.R.; Ahmad, S.; Hashim, U.R. The effectiveness of gamification technique for higher education students' engagement in polytechnic Muadzam Shah Pahang, Malaysia. Int. J. Educ. Technol. High. Educ. 2018, 15, 41. [CrossRef]

12. Lee, B.C. The effect of gamification on psychological and behavioral outcomes: Implications for cruise tourism destinations. Sustainability 2019, 11, 3002. [CrossRef]

13. Sipone, S.; Abella-García, V.; Barreda, R.; Rojo, M. Learning about sustainable mobility in primary schools from a playful perspective: A focus group approach. Sustainability 2019, 11, 2387. [CrossRef]

14. Boboc, R.G.; Duguleană, M.; Voinea, G.-D.; Postelnicu, C.-C.; Popovici, D.-M.; Carrozzino, M. Mobile augmented reality for cultural heritage: Following the footsteps of Ovid among different locations in Europe. Sustainability 2019, 11, 1167. [CrossRef]

15. Hawi, N.S.; Samaha, M. To excel or not to excel: Strong evidence on the adverse effect of smartphone addiction on academic performance. Comput. Educ. 2016, 98, 81-89. [CrossRef]

16. Tossell, C.C.; Kortum, P.; Shepard, C.; Rahmati, A.; Zhong, L. You can lead a horse to water but you cannot make him learn: Smartphone use in higher education. Br. J. Educ. Technol. 2015, 46, 713-724. [CrossRef]

17. Van Krevelen, D.W.F.; Poelman, R. A survey of augmented reality technologies, applications and limitations. Int. J. Virtual Real. 2010, 9, 1-20.

18. Lu, S.-J.; Liu, Y.-C. Integrating augmented reality technology to enhance children's learning in marine education. Environ. Educ. Res. 2015, 21, 525-541. [CrossRef]

19. Fifth Star Labs. Available online: https://www.fifthstarlabs.com/ (accessed on 27 May 2018).

20. PlantSnap. Available online: https://www.plantsnap.com/ (accessed on 6 May 2018).

21. Monash Rocks. Available online: https://www.monash.edu/elab/content/ar-monash-rocks-app (accessed on 7 May 2018).

22. Khan, A.; Ahmad, F.H.; Malik, M.M. Use of digital game based learning and gamification in secondary school science: The effect on student engagement, learning and gender difference. Educ. Inf. Technol. 2017, 22, 2767-2804. [CrossRef]

23. Yang, X.; Chen, J. Using discovery maps as a free-choice learning process can enhance the effectiveness of environmental education in a botanical garden. Environ. Educ. Res. 2017, 23, 656-674. [CrossRef]

24. Eisenack, K. A climate change board game for interdisciplinary communication and education. Simul. Gaming 2013, 44, 328-348. [CrossRef]

25. Savic, D.A.; Morley, M.S.; Khoury, M. Serious gaming for water systems planning and management. Water 2016, 8, 456. [CrossRef]

26. Davis, F.D. Perceived usefulness, perceived ease of use, and user acceptance of information technology. MIS Q. 1989, 13, 319-340. [CrossRef]

27. Teo, T. Technology Acceptance in Education; SensePublishers: Rotterdam, The Netherlands, 2011.

28. Taylor, S.; Todd, P.A. Understanding information technology usage: A test of competing models. Inf. Syst. Res. 1995, 6, 144-176. [CrossRef]

29. Venkatesh, V.; Morris, M.G.; Davis, G.B.; Davis, F.D. User acceptance of information technology: Toward a unified view. MIS Q. 2003, 27, 425-478. [CrossRef]

30. Bothma, C.H.; Cant, M.C. Adopting learning technologies: From belief to practice. Educ. Stud. 2011, 37, 375-389. [CrossRef]

31. Teo, T. Examining the intention to use technology among pre-service teachers: An integration of the technology acceptance model and theory of planned behavior. Interact. Learn. Environ. 2012, 20, 3-18. [CrossRef]

32. Creswell, J.W.; Plano Clark, V.L. Designing and Conducting Mixed Methods Research, 2nd ed.; Sage: Thousand Oaks, CA, USA, 2011.

33. Bolton, K.; Botha, W. English in China's universities: Past and present. World Engl. 2015, 34, $190-210$. [CrossRef]

34. Palinkas, L.A.; Horwitz, S.M.; Green, C.A.; Wisdom, J.P.; Duan, N.; Hoagwood, K. Purposeful sampling for qualitative data collection and analysis in mixed method implementation research. Adm. Policy Ment. Health Ment. Health Serv. Res. 2015, 42, 533-544. [CrossRef]

35. Bressler, D.M.; Bodzin, A.M. A mixed methods assessment of students' flow experiences during a mobile augmented reality science game. J. Comput. Assist. Learn. 2013, 29, 505-517. [CrossRef] 
36. Zheng, D.; Liu, Y.; Lambert, A.; Lu, A.; Tomei, J.; Holden, D. An ecological community becoming: Language learning as first-order experiencing with place and mobile technologies. Linguist. Educ. 2018, 44, 45-57. [CrossRef]

37. Perry, B. ARIS: A tool to promote language learning through AR gaming. CALICO J. 2018, 35, 333-342. [CrossRef]

38. Field Day Lab. Available online: https://fielddaylab.org/make/aris/ (accessed on 27 August 2018).

39. Emerson, R.M.; Fretz, R.I.; Shaw, L.L. Writing Ethnographic Fieldnotes, 2nd ed.; University of Chicago Press: Chicago, IL, USA, 2011.

40. Chau, P.Y.K.; Hu, P.J.-H. Information technology acceptance by individual professionals: A model comparison approach. Decis. Sci. 2001, 32, 699-719. [CrossRef]

41. Teo, T. Modelling technology acceptance in education: A study of pre-service teachers. Comput. Educ. 2009, 52, 302-312. [CrossRef]

42. Brown, G.T.L. Measuring attitude with positively packed self-report ratings: Comparison of agreement and frequency scales. Psychol. Rep. 2004, 94, 1015-1024. [CrossRef]

43. Nunnally, J.C. Psychometric Theory, 2nd ed.; McGraw-Hill: New York, NY, USA, 1978.

44. Creswell, J.W.; Miller, D.L. Determining validity in qualitative inquiry. Theory Pract. 2000, 39, $124-130$. [CrossRef]

45. Hsieh, H.-F.; Shannon, S.E. Three approaches to qualitative content analysis. Qual. Health Res. 2005, 15, 1277-1288. [CrossRef] [PubMed]

46. Markaki, V. Environmental education through inquiry and technology. Sci. Educ. Int. 2014, $25,86-92$.

47. Uzunboylu, H.; Cavus, N.; Ercag, E. Using mobile learning to increase environmental awareness. Comput. Educ. 2009, 52, 381-389. [CrossRef]

48. Selwyn, N. Minding our language: Why education and technology is full of bullshit ... and what might be done about it. Learn. Media Technol. 2016, 41, 437-443. [CrossRef]

49. Chang, C.-S.; Chen, T.-S.; Hsu, W.-H. The study on integrating WebQuest with mobile learning for environmental education. Comput. Educ. 2011, 57, 1228-1239. [CrossRef]

50. Ruchter, M.; Klar, B.; Geiger, W. Comparing the effects of mobile computers and traditional approaches in environmental education. Comput. Educ. 2010, 54, 1054-1067. [CrossRef]

51. Laurie, R.; Nonoyama-Tarumi, Y.; Mckeown, R.; Hopkins, C. Contributions of education for sustainable development to quality education: A synthesis of research. J. Educ. Sustain. Dev. 2016, 10, $226-242$. [CrossRef]

52. Dirkx, J.M. The power of feelings: Emotion, imagination, and the construction of meaning in adult learning. New Dir. Adult Contin. Educ. 2001, 2001, 63-72. [CrossRef]

53. Downing, K. Personality and Online Learning. In Cases on Interactive Technology Environments and Transnational Collaboration: Concerns and Perspectives; Mukerji, S., Tripathi, P., Eds.; IGI: Hershey, PA, USA, 2001; pp. 126-139. 